\title{
Maternidade atrás das grades
}

Recebido em: 30/09/2010

Aceito em: 20/01/2011

Estudo com objetivo de conhecer as vivências da maternidade em situação de prisão e as condições de saúde infantil no sistema prisional. Trata-se de uma pesquisa qualitativa realizada com oito mulheres que vivenciam a maternidade na Penitenciária Feminina do Rio Grande do Sul. Da análise foram elencadas as categorias: "Eu descobri a maternidade no sistema prisional" e "Ninguém pensa em nada melhor para a gente - saúde, condições para os filhos... isso não vai mudar". A investigação permitiu desvelar a necessidade de discutir a saúde materno-infantil no sistema penitenciário brasileiro.

Descritores: Saúde Materno-Infantil, Prisões, Mulheres Encarceradas, Assistência à Saúde Materno-Infantil.

\section{Maternity behind bars}

This study aims to understand the experience of maternity in a state of prison and child health conditions in prisons. That is a qualitative research carried out with eight women who experience maternity at women's penitentiary in Rio Grande do Sul. The analysis categories were listed:

"I found the maternity out in the prison system" and "Nobody thinks of anything better for us - health conditions in favor of children... it will not change". The investigation reveals the need to discuss the maternal and child health in the Brazilian penitentiary system.

Descriptors: Maternal and Child Health, Prisons, Incarcerated Women, Assistance to Maternal and Child Health.

\section{La maternidad tras las rejas}

Este estudio tuvo como objetivo comprender la experiencia de la maternidad en una prisión del estado y las condiciones de salud de los niños en las cárceles. Se trata de una investigación cualitativa realizada con ocho mujeres que experimentan la maternidad penitenciaria en Río Grande do Sul. Las categorías de análisis se incluyeron: "He encontrado maternidad en el sistema penitenciario" y "Nadie piensa en otra cosa mejor para nosotros salud, condiciones a favor de los hijos... no va a cambiar". En la investigación revelan la necesidad de discutir la salud materno-infantil en el sistema penitenciario brasileño.

Descriptores: Salud Materno-Infantil, Prisiones, Mujeres Encarceladas, Asistencia a la Salud Materno-Infantil.

\section{INTRODUÇÃO}

A atenção à saúde no sistema prisional tem sido abordada de maneira reducionista, uma vez que as ações se limitam àquelas focadas em doenças sexualmente transmissíveis, uso de álcool e drogas e campanha para imunização. Diante dessa problemática, foi instituído o Plano Nacional de Saúde no Sistema Penitenciário (PNSSP), com a finalidade de prover a atenção integral à população carcerária e reorientar as práticas de saúde no sistema penitenciário(1), assegurando a eficácia das ações de promoção, prevenção e atenção integral à saúde. A execução do PNSSP é considerada um avanço para a saúde no sistema penitenciário, porém a saúde da mulher que vivencia o período grávido-puerperal sob esse sistema ainda é pouco abordada.

Frente às lacunas na atenção à saúde materno-infantil carcerária, em 2009 foi instituída a lei no $11942^{(2)}$, que assegura às mães presas e a seus bebês condições mínimas de assistência. Essas legislações reafirmam alguns direitos da mulher em situação de prisão e de seus filhos e, acima de tudo, a necessidade de que se tenha uma assistência diferenciada e qualificada para o cuidado maternoinfantil. Considerando que a saúde é um direito legítimo de cidadania, garantido pela Constituição Brasileira, e um princípio fundamental do PNSSP, acredita-se que as ações de saúde nesse contexto deveriam ser mais divulgadas e exercidas por uma rede profissional qualificada de apoio à população carcerária feminina brasileira.

A partir da prática assistencial e docente das pesquisadoras em relação à saúde da mulher e da criança, percebeu-se a necessidade de trazer essa questão da saúde do sistema prisional para os debates acadêmicos. Nesse contexto, investigar as condições de saúde e assistência de

1 Enfermeira. Especialista em Enfermagem Obstétrica pela Universidade do Vale do Rio dos Sinos. Professora Substituta do Departamento Materno-Infantil da Universidade Federal do Rio Grande do Sul/RS, Brasil. E-mail: evelinefranco@yahoo.com.br.

2 Enfermeira. Doutora em Educação pela Pontifícia Universidade Católica do Rio Grande do Sul. Professora Titular do Curso de Enfermagem da Universidade do Vale do Rio dos Sinos/RS. E-mail: familialuz@cpovo.net.

3 Enfermeira. Licenciada em Enfermagem pela Universidade Luterana do Brasil. Mestre em Medicina Tropical da Universidade Federal de Goiás. Professora do Curso de Enfermagem da Faculdade Nossa Senhora de Fátima, Caxias do Sul/RS. E-mail: fhcecchetto@gmail.com. 
cuidado materno-infantil torna-se relevante, uma vez que a reflexão sobre as práticas de saúde no âmbito prisional pode sugerir melhorias de atenção integral à saúde da mulher e da criança.

Frente ao exposto, o estudo tem por objetivo conhecer as vivências da maternidade em situação de prisão e as condições de saúde materno-infantil no sistema prisional.

\section{METODOLOGIA}

Trata-se de uma pesquisa qualitativa, do tipo exploratóriodescritiva, capaz de ajustar-se no decorrer de sua realização mediante o entendimento do todo, do envolvimento profundo do pesquisador com o campo, e a valorização da subjetividade ${ }^{(3)}$.

O campo de estudo foi a Galeria Creche da Penitenciária Feminina Madre Pelletier (PFMP), que aloja gestantes após o oitavo mês, aquelas que apresentam risco gestacional e mulheres com seus filhos.

Durante o período de coleta, a galeria abrigava 22 mães, 22 crianças e duas gestantes. Treze mulheres aceitaram participar do estudo, porém quatro não puderam participar por não terem cumprido as práticas disciplinares da prisão.

A partir da sétima entrevista, os dados começaram a apresentar redundância. Dessa forma, utilizando-se o critério de saturação de $\operatorname{dados}^{(4)}$, a amostra constituiu-se em duas gestantes e seis mulheres que vivenciaram a gestação no sistema prisional.

Foram consideradas como participantes de um modo único gestantes e mulheres que já haviam passado pela gestação, pois o foco não foi a gestação e maternidade separadas, mas sim como uma experiência de um mesmo fenômeno - a maternidade -, que inclui a gestação, o nascimento e o tornarse mãe. Acredita-se, desse modo, que diferentes sujeitos podem, por meio de narrativas, contribuir para a compreensão do fenômeno.

A coleta das informações ocorreu por meio de entrevistas semiestruturadas, um dos principais meios de investigação para coletar dados com enfoque qualitativo $^{(5)}$. O cenário das entrevistas foram as instalações do presídio, no período de janeiro a fevereiro de 2010, em horários previamente agendados, sendo preservada a privacidade, evitando-se interrupções.

Para a organização e o tratamento das informações, utilizou-se a versão 7.0 do QSR Nvivo, programa que auxilia na análise de dados qualitativos por dispor de ferramentas de codificação e armazenamento de texto em categorias. Os dados foram estudados por meio do método de análise de conteúdo do tipo temática, seguindo as fases de préanálise, exploração do material e tratamento, inferência e interpretação dos resultados obtidos ${ }^{(5)}$.

Esta pesquisa, autorizada pela Superintendência dos
Serviços Penitenciários do Rio Grande do Sul, contemplou a resolução 196/1996 e teve aprovação do Comitê de Ética em Pesquisa da Universidade do Vale do Rio dos Sinos, sob o parecer $n^{\circ} 09 / 118$. Às mulheres que aceitaram espontaneamente participar da pesquisa foi solicitada assinatura no Termo de Consentimento Livre e Esclarecido.

Para respeitar o anonimato, utilizou-se a abreviação " $E$ " (de entrevistada), seguido do número de ordem, para a especificação das participantes.

\section{RESULTADOS}

$\mathrm{Na}$ análise dos dados, verificou-se que cinco mulheres eram de Porto Alegre, uma da região metropolitana e duas do interior do Rio Grande do Sul. Quanto à idade, tinham entre 19 e 33 anos; quatro delas eram solteiras e as demais casadas, sendo que seus companheiros também estão cumprindo pena nas penitenciárias masculinas do estado. As entrevistadas têm escolaridade de sete anos de estudo em média. Além dos afazeres domésticos, em situação prévia à prisão, desempenhavam atividades laborais de baixa remuneração com renda familiar de $R \$ 800$ e residiam com familiares ou amigos. Três entrevistadas estavam em situação jurídica provisória, cinco condenadas de quatro a 11 anos de prisão, todas em razão da lei 1343/2006, denominada "Nova Lei de Drogas", enquadrando-se no artigo 33 (tráfico e crimes assemelhados) ${ }^{(6)}$.

Quanto aos aspectos reprodutivos, uma havia completado sete meses de gestação, outra estava com nove meses e seis tinham seus filhos na creche da penitenciária. O número de filhos variou de um a quatro e os que vivem com os familiares têm idade entre 1 e 11 anos. Quanto à idade das crianças que permaneciam junto a suas mães, uma possuía 11 meses de idade, duas, 10 meses, e três eram recém-nascidas.

$\mathrm{Na}$ análise da vivência da maternidade em situação de prisão e as condições de saúde infantil no sistema prisional, foram elencadas as categorias: “Eu descobri a maternidade no sistema prisional" e "Ninguém pensa em nada melhor para a gente - saúde, condições para os filhos... isso não vai mudar".

\section{"Eu descobri a maternidade no sistema prisional"}

O tempo de permanência é um fator preocupante das mulheres em situação de prisão que foram entrevistadas, conforme se evidencia na fala de uma das participantes.

"Muitas aqui não têm para onde mandar os filhos. A preocupação é que muitas vão ter que mandar os filhos para um abrigo, né? Até a mãe poder sair, até a mãe poder pegar... Imagina! Que referência a criança vai ter?" (E5)

Mesmo com essa preocupação, algumas mulheres acreditam que o período da criança no sistema prisional não deve se estender por muitos anos em razão das condições inadequadas do ambiente ao desenvolvimento infantil. 
"O tempo de permanência não pode ser muito por causa desse ambiente, né? [...] não dá para esquecer que aqui as crianças são presas também [...] devia ser um ambiente um pouco mais habitual para as crianças." (E8)

Percebe-se que a permanência da criança dentro da prisão suaviza a pena, pois essas mulheres não se sentem sozinhas e suprem a falta dos outros filhos deixados no mundo extramuros da prisão.

"Não imagino tendo que mandar ela embora, né? Porque, de certa forma, para mim, está sendo mais tranquilo, entende? Parece que os dias estão passando mais rapidamente porque eu tenho um entretenimento. Eu tenho ela, já não sou sozinha, né? Não estou sozinha porque ela supre um pouco a falta que meus outros filhos me fazem [chorando]." (E5)

Embora essas mulheres tenham a possibilidade da companhia e do cuidado do filho nascido no ambiente prisional, constata-se que os filhos deixados fora da prisão são preocupações constantes para elas.

"Eu fico pensando, conforme o tempo vai passando, como é que eu vou ficar aqui com minha filha?

Quero ir embora, tenho meus filhos para criar." (E5)

"Preocupação... Só com meus filhos lá fora." (E6)

"A minha filha está bem cuidada, mas a minha preocupação é que eu queria estar com ela." (E8)

Entre a preocupação relacionada ao tempo de permanência da criança e a pena suavizada pela presença do filho, as protagonistas do estudo revelam a culpabilidade.

"O que eu acho... Acho que eu errei, né? Ele não tem culpa de ficar aqui, se com 6 tem que mandar embora, eu vou mandar. Ele não tem culpa." (E1)

Apesar disso, algumas mulheres vivenciam a reclusão junto ao filho como descoberta da maternidade.

"Aqui na creche... eu descobri ser mãe. [...] Para mim é diferente porque eu sempre dependi de empregada para cuidar dos meus filhos. Então para mim está sendo uma experiência diferente, gostosa, eu estou aprendendo com meu filho a cada minuto. Para mim está sendo mágica a vivência aqui com meu filho, né?" (E3)

De acordo com as funcionárias da instituição, muitas vezes é no cárcere que, pela primeira vez, essas mulheres cuidam do filho, dispensando atenção a eles no cuidado integral com a higiene, a troca de fraldas, a amamentação e o carinho, fazendo com que realmente se sintam mães.

\footnotetext{
“Ninguém pensa em nada melhor para a gente - saúde, condições para os filhos... isso não vai mudar"

As participantes do estudo demonstraram, em especial, preocupações relacionadas ao aleitamento materno por reconhecerem ser fonte protetora de condições de saúde e que não pode ser dispensada nesse ambiente pouco
}

favorável ao crescimento e desenvolvimento de um bebê.

"A única coisa que me preocupa é o leite. Estão dizendo que seca em três, quatro dias se ele não mamar. Só que não dá, sai muito sangue, aí ele vomita o sangue com o leite. É a única coisa que está me preocupando." (E4)

"Eu vou fazer de tudo para minha filha não largar o peito, eu só deixo o peito, mais nada." (E5)

"Aqui eu tive a grande dificuldade, que é a do leite. Foi uma coisa que eu chorei bastante, sabe? Secou o leite. [...] Eu entrei em desespero, chorei bastante. [...] A maior tristeza que eu tive aqui dentro foi isso aí [leite secar]." (E7)

Essas mulheres enfrentam dificuldades relacionadas à lactação e não possuem suporte especializado para superar os problemas comuns do aleitamento materno. Além disso, evidencia-se que tanto a amamentação quanto a alimentação não ocorrem da forma mais adequada para a saúde das crianças na penitenciária.

"Depois de uma certa idade eles [filhos] começam a ter os potinhos deles de comida, mas a comida não vem apropriada para a idade deles, não é comida para criança. Vem um arroz queimado, uma massa que nem chiclete, um feijão queimado. Isso tinha que melhorar bastante." (E8)

O ambiente inadequado para o crescimento e desenvolvimento de uma criança e a falta de recursos e apoio familiar para a assistência à saúde da criança são constantes preocupações entre as mães presas. Em seus relatos, é explícito o medo de que seus filhos adoeçam.

"Só tenho medo que ela [bebê] fique doente. [...] Então eu estou sempre em cima dela, sempre cuidando, limpando, não deixo pegar um ventinho, né?" (E5)

"Tenho muito medo de o meu nenê ficar doente aqui dentro. [...] Porque aqui é um lugar muito sujo, né? Bactéria, tudo que é coisa ruim aqui tem. Eu tenho medo. Aqui, de $100 \%$ das crianças, 70\% têm bronquiolite. [...] Aqui não é arejado, fica mais fácil de as crianças pegarem doença." (E7)

As condições físicas da penitenciária não favorecem o desenvolvimento saudável das crianças, uma vez que muitas apresentam doenças respiratórias.

"Aqui, a maioria das crianças tem bombinha, faz nebulização, tem um tubo de oxigênio lá em cima, quase todas as crianças têm de usar, são doentes." (E5)

Evidencia-se que a integralidade à saúde da criança é prejudicada. Como os atendimentos à saúde da criança ocorrem nas unidades de saúde do município, as mães não podem participar das consultas com os profissionais de saúde. Aquelas que possuem condições e suporte familiar buscam atendimento à saúde de seus filhos por meio dos recursos familiares para levar a criança.

"Para as crianças aqui tem um médico, mas que não é pediatra. $E$, quando tem alguma criança com alguma coisa, ele olha. Mas essas coisas que é normal de pesar, medir, examinar... Isso nossos filhos não têm. [...] Quando alguma criança tem 
alguma coisa, eles levam fora para ver o que é." (E3)

"Aqui dentro ela [bebê] não teve atendimento. Toda vez que eu vejo que ela tem alguma coisa, minha mãe pega ela e leva no médico da rua, aqui dentro não tem como. [...] Mas eu não sei exatamente como é, porque não estou junto, né? Só sei o que eles me passam." (E2)

"Com 4 meses, ele [filho] andava assim, chorão, tinha uma tosse também, a respiração dele para mim parecia que não era normal. Mas aí, como tinha muita criança daqui no hospital com bronquiolite e as funcionárias estavam muito... assim... ocupadas, pedi para ligarem lá para a avó dele, para ela vir buscar ele. Ela veio, levou ele no médico, daí era o ouvido." (E8)

Nas falas das mães, fica evidente que o atendimento às crianças é precário, e a participação delas no cuidado dos filhos, em alguns momentos, é impedida.

\section{DISCUSSÃO}

As características sociodemográficas das participantes da pesquisa são semelhantes às descritas em outros estudos com mulheres em situação de prisão(7-8).

Discutir o vínculo mãe-bebê nas penitenciárias brasileiras é polêmico, pois, se por um lado separação entre mãe e filho é muito dolorosa, por outro a inadequação do espaço prisional pode afetar o desenvolvimento da criança. A legislação brasileira não define período mínimo de permanência da criança junto à mãe reclusa, mas assegura à criança o direito de ficar junto à mãe durante o período de amamentação ${ }^{(2,9)}$.

Entre os aspectos que envolvem a maternidade atrás das grades existe a problemática de a mãe perder o contato e vínculos afetivos com os filhos e a família. Por isso, propõese que as mulheres em situação de prisão com filhos de até 12 anos tenham a visita desses garantida pelo Estado, incluindo-se o custo de deslocamento ${ }^{(10)}$. Porém, isso não é uma realidade brasileira. Inclusive, as crianças nem sempre residem no mesmo município das penitenciárias, como constatado neste estudo, dificultando ainda mais as possibilidades de visitas.

Desde o momento em que adentram a prisão, as mulheres sentem-se culpadas por não poder cuidar dos filhos como gostariam $^{(11)}$, por estarem longe deles ou por fazê-los passar pela restrição de liberdade. Há evidências de que mulheres em situação de prisão tendem a apresentar mais sintomas depressivos do que aquelas que não têm filhos ${ }^{(12)}$. A culpabilidade, as preocupações referentes à permanência da criança no ambiente prisional e o cuidado e sustento dos filhos deixados sob a guarda dos familiares são questões que podem levar essas mulheres a transtornos emocionais e psiquiátricos.

Constata-se que a maternidade é um sofrimento para as mulheres confinadas, por ficarem impedidas de exercer o papel de mães ${ }^{(13)}$. Além de não garantir às apenadas a possibilidade de exercerem a maternidade de modo apropriado, a prisão impede o convívio com outros filhos. O amor materno é algo construído, conquistado, e não apenas instintivo da mulher ${ }^{(14)}$. Desse modo, a produção de ambientes favoráveis para a formação do vínculo entre mãe e filho torna-se necessária.

A maternidade exige aprendizado e o vínculo entre mãe e filho precisa ser fortalecido desde o pré-natal, o que ainda não garante o sucesso do aleitamento materno. As primeiras duas semanas de amamentação podem ser uma fase muito difícil, principalmente para as mães que estão amamentando pela primeira vez. Nesse sentido, seria importante que as mulheres recebessem assistência de saúde que favoreça o aprendizado da maternagem, envolvendo o aleitamento materno e cuidados com o recém-nascido.

A dificuldade de amamentar vivenciada pelas mulheres é uma das principais causas do desmame precoce ${ }^{(15)}$, por isso é importante que elas sejam orientadas, esclarecidas e incentivadas nesse período. $\mathrm{O}$ aleitamento materno exclusivo previne diabetes melito, sobrepeso e obesidade, protege contra a síndrome da morte súbita, reduz a incidência e gravidade de morbidades como diarreia, infecções respiratórias e enterocolite necrotizante, entre outras doenças da infância ${ }^{(16)}$. Para a saúde da mulher, a amamentação atua como efeito protetor para os cânceres de mama e ovário, fraturas por osteoporose, retorno ao peso pré-gestacional mais rapidamente e duração da amenorreia lactacional ${ }^{(15)}$. A importância dessa prática passa tanto pelos custos no orçamento familiar quanto pelas despesas do Estado. Assim, o aleitamento materno constitui-se em uma medida preventiva de saúde pública.

Ao receber a criança na prisão, o Estado também deve proporcionar alimentos complementares apropriados à continuidade da amamentação, até os 2 anos de idade ou mais, dando ênfase a esses conceitos nos canais de divulgação social, a fim de induzir as comunidades a desenvolverem essas práticas ${ }^{(10,17)}$. Para uma alimentação saudável das crianças menores de 2 anos, somente uma alimentação variada (colorida) evita a monotonia da dieta e garante a quantidade de ferro e vitaminas de que a criança necessita para manter saúde e crescimento adequados ${ }^{(17)}$.

Crianças que vivem com a mãe em situação de prisão representam um grupo vulnerável, com necessidades de saúde particulares ${ }^{(18-19)}$. Embora o Estado seja responsável pela assistência da criança que permanece com a mãe no sistema prisional, a maioria das prisões não oferece condições adequadas nem dispõe de profissionais especializados para o atendimento das mães e seus filhos ${ }^{(20)}$. Durante a permanência da criança na penitenciária, ela deverá ser assistida integralmente, devendo ser realizado o acompanhamento do crescimento e desenvolvimento da criança e a assistência de saúde por meio de consultas, exames e vacinas ${ }^{(10)}$. 


\section{CONSIDERAÇÕES FINAIS}

Discutir a saúde materno-infantil no sistema penitenciário brasileiro é um desafio complexo, pois esse universo permanece esquecidoem políticas públicas e debates acadêmicos.Contudo, esta investigação permitiu dar visibilidade ao fenômeno da maternidade atrás das grades e atenção à saúde dos filhos das mulheres que permanecem com elas na penitenciária.

As protagonistas do estudo revelaram que a maternidade em situação de prisão é caracterizada por preocupações relacionadas às condições ambientais em que vivem seus filhos dentro da penitenciária, à assistência de saúde oferecida a essas crianças e à distância do cuidado dos filhos deixados do lado de fora da prisão. A partir das falas dessas mulheres, constata-se que o cuidado materno-infantil no sistema prisional se encontra insuficiente e contraditório em relação aos princípios do Sistema Único de Saúde.

\section{Referências}

1. Ministério da Saúde (BR). Plano Nacional de Saúde no Sistema

Penitenciário. Portaria Interministerial n 1777 de 9 de novembro de 2003. Brasília: Ministério da Saúde; 2004.

2. Presidência da República (BR). Lei n 11942, de 28 de maio de 2009: dá nova redação aos arts. 14, 83 e 89 da Lei n॰ 7210, de 11 de julho de 1984 - Lei de Execução Penal, para assegurar às mães presas e aos recémnascidos condiçōes mínimas de assistência [Internet]. [citado 2009 Jun 09]. Disponível em: http://www.planalto.gov.br/ccivil/_Ato2007-2010/2009/Lei/ L11942.htm.

3. Polit DF, Beck CT, Hungler BP. Fundamentos de pesquisa em enfermagem. 5a ed. Porto Alegre: Artes Médicas; 2004.

4. Fontanella BJB, Ricas J, Turato ER. Amostragem por saturação em pesquisas qualitativas em saúde: contribuições teóricas. Cad Saude Publica. 2008;24(1):17-27.

5. Bardin L. Análise de conteúdo. Lisboa: Edições 70; 2004.

6. Presidência da República (BR). Lei n॰ 11343, de 23 de agosto de 2006: institui o Sistema Nacional de Políticas Públicas sobre Drogas - Sisnad; prescreve medidas para prevenção do uso indevido, atenção e reinserção social de usuários e dependentes de drogas; estabelece normas para repressão à produção não autorizada e ao tráfico ilícito de drogas; define crimes e dá outras providências [lnternet]. [citado 2009 Jun 09]. Disponível em: http://www. planalto.gov.br/ccivil_03/_ato2004-2006/2006/lei/111343.htm.

7. Soares BM, llgenfritz I. Prisioneiras: vida e violência atrás das grades. Rio de Janeiro: Garamond; 2002.

8. Wolff M, Oliveira F, Moraes M, Giugliani S. Mulheres e prisão: a experiência do observatório de direitos humanos da Penitenciária Feminina Madre Pelletier. Porto Alegre: Dom Quixote; 2007.

9. Presidência da República (BR). Lei n 8069, 13 de julho de 1990. Dispōe sobre o Estatuto da Criança e do Adolescente e dá outras providências. Diário Oficial da República Federativa do Brasil, 16 de julho de 1990.
10. Presidência da República (BR). Secretaria Especial de Políticas para as Mulheres. Grupo de trabalho interministerial - reorganização e reformulação do sistema prisional feminino - 2008. Brasília: [s.n.]; 2008. 11. Antony C. Mujeres invisibles: las cárceles femeninas en América Latina. Nueva Sociedad. 2007;(208):73-96.

12. Mello DC. Quem são as mulheres encarceradas? [dissertação]. Porto Alegre: Pontifícia Universidade Católica do Rlo Grande do Sul; 2008.

13. Lima M. Da visita íntima à intimidade da visita: a mulher no sistema prisional [mestrado]. São Paulo: Universidade de São Paulo; 2006.

14. Badinter E. Um amor conquistado: O mito do amor materno. $5^{\text {a }}$ ed. Rio de Janeiro: Nova Fronteira; 1985.

15. Caminha MFC, Serva VB, Arruda IKG, Batista Filho M. Aspectos históricos, científicos, socioeconômicos e institucionais do aleitamento materno. Rev Bras Saude Matern Infant. 2010;10:25-37.

16. Fujimori E, Minagawa ÁT, Laurenti D, Montero RMJM, Borges ALV, Oliveira IMV. Duração do aleitamento materno em menores de 2 anos de idade em Itupeva, São Paulo, Brasil: há diferenças entre os grupos sociais? Rev Bras Saude Matern Infant. 2010;10:39-49.

17. Ministério da Saúde (BR). Secretaria de Política de Saúde. Organização Pan-Americana da Saúde. Guia alimentar para crianças menores de 2 anos. Brasília: Ministério da Saúde; 2002.

18. Ferrara P, Emmanuele V, Nicoletti A, Mastrangelo A, Marrone G, Pedote G. Mothers with their babies in prison: the first Italian experience. Arch Dis Child. 2006;92:183-7.

19. Martin SL, Rieger RH, Kupper LL, Meyer RE, Qaqish BF. The effect of Incarceration during pregnancy on birth outcomes. Public Health Rep. 1997;112:340-6.

20. Santa Rita RP. Mães e crianças atrás das grades: em questão o princípio da dignidade da pessoa humana [mestrado]. Brasília: Universidade de Brasília; 2006. 